\title{
OBLICZANIE NAPIĘCIA NA PANTOGRAFIE ELEKTRYCZNEGO POJAZDU TRAKCYJNEGO, PRĄDÓW OBCIĄŻENIOWYCH I ZWARCIOWYCH W SIECI TRAKCYJNEJ
}

\author{
Włodzimierz Kruczek \\ Instytut Kolejnictwa, Zakład Elektroenergetyki
}

Streszczenie. Elektryczne pojazdy trakcyjne do niezawodnej pracy i utrzymywania osiagów eksploatacyjnych, na które zostaty zaprojektowane, wymagaja niezawodnego zasilania. Zasilanie to jest gwarantowane poprzez system zasilania trakcyjnego. Cecha charakterystyczna dla obciażen trakcyjnych jest ich duża zmienność, pobór prądu przez pojazd trakcyjny dużej mocy, przy niedostosowanym układzie zasilania jak i niedostosowanej sieci trakcyjnej powoduje zbyt duży spadek napięcia na pantografie, przez co pojazd traci właściwości trakcyjne, na które zostat zaprojektowany. Niniejszy artykut poświęcony jest programowi napisanemu $w$ środowisku MATHCAD do obliczania napięcia na pantografie elektrycznego pojazdu trakcyjnego, który zmienia swoje położenie, oraz obliczania prądów obciażeniowych i zwarciowych w sieci trakcyjnej.

Słowa kluczowe: trakcja elektryczna, zasilanie elektrycznych pojazdów trakcyjnych

\section{THE ELECTRICAL CHARACTERISTICS OF A CATENARY SYSTEM IN ELECTRIC RAIL VEHICLES, THE CALCULATION OF TRACTION LOAD AND SHORT - CIRCUIT CURRENTS}

\begin{abstract}
Electrical railway vehicles need a reliable power source to comply with their designed specification. The specific working range of the electric traction system includes the big changes in the load during operation. A big power consumption in conjunction with the insufficient network can cause the loss of the vehicle's power. This problem is also addressed by the interoperability specification. The MATHCAD is used mainly for numerical calculations. The program simulates network with two power substations and two track sectioning cabins. It can also calculation single-sided network. The calculation step can be set from $1 \mathrm{~m}$ up to $1000 \mathrm{~m}$. This is important for networks containing sections of different resistance. The calculation can be performed in three different variations: with constant current, constant vehicle resistance and with the set vehicle's speed and parameters. It is also capable of calculating the short-circuit current. The program interface enables the user unfamiliar to MATHCAD to perform the calculations. The user needs only to input data to pre-defined fields and tables. The results can be exported into other programs.
\end{abstract}

Keywords: traction power supplies, electric vehicles

\section{Wstęp}

Częściami składowymi systemu zasilania trakcyjnego są: system energetyczny, podstacje trakcyjne, kabiny sekcyjne i sieć trakcyjna. Żeby system zasilania kolejowej trakcji elektrycznej był wydajny i spełniał wymogi interoperacyjności, muszą być spełnione parametry techniczne określone w Technicznej Specyfikacji Interoperacyjności „Energia” [1] oraz w powołanych w niej normach. Najważniejsze z nich to:

- napięcie średnie użyteczne na pantografie (U Sr_uz $\geq 2700$ V) [3];

- napięcie minimalne na pantografie (U $\min 1 \geq 2000 \mathrm{~V})$ [3];

- prąd zwarcia w warunkach najbardziej niekorzystnych (Izw $\geq 2800$ A) $[1,3]$.

Przy wyliczaniu powyższych parametrów nieocenioną pomoc stanowią programy obliczeniowe. Niniejszy artykuł poświęcony jest programowi obliczeniowemu napisanemu do tego celu w środowisku MATHCAD.

\section{Ogólna charakterystyka metody obliczeń}

MATCAD należy do grupy programów określanych mianem systemów algebry komputerowej, programy te są wynikiem pracy nad sztuczną inteligencją. (Computer Algebra System, CAS). Służy on do komputerowego wspomagania obliczeń symbolicznych w matematyce i dyscyplinach technicznych, oraz przede wszystkim do przeprowadzenia obliczeń numerycznych tzn. takich których wynikami sa liczby lub wartości wielkości fizycznych. MATCAD ma również wbudowany własny język programowania, dzięki temu można $\mathrm{w}$ procesie rozwiązywania problemów matematycznych i inżynieryjnych wykorzystywać własne algorytmy i tworzyć programy użytkowe. Dzięki tej właściwości MATCAD może być wykorzystywany jako zintegrowane środowisko programistyczne, czyli aplikacja służąca do tworzenia, modyfikowania, testowania i konserwacji oprogramowania użytkowego. Cecha ta została wykorzystana w programie obliczającym napięcie i prądy w sieci trakcyjnej.

Obliczenia przeprowadzane są $\mathrm{z}$ uwzględnieniem wobliczeniach dwóch podstacji trakcyjnych i dwóch kabin sekcyjnych. Sytuacja taka przedstawiona jest na rysunku 1 . Pogram umożliwia również analizę dla zasilania jednostronnego oraz z jedną kabiną sekcyjną, lub bez kabiny sekcyjnej. Możliwe jest również uwzględnienie „dosilenia" ze znakiem + (prądy wpływające), lub ze znakiem - (prądy wypływające) z lub do analizowanego odcinka. „Dosilenie" analizowanego odcinka ze znakiem + lub - może być stałe lub mieć charakter funkcji nieliniowej, której przebieg zależy od sytuacji ruchowej na sąsiednich odcinkach. Rysunek 2 przedstawia schemat zastępczy, w którym wykonywane są obliczenia dla dwóch podstacji trakcyjnych i dwóch kabin sekcyjnych.

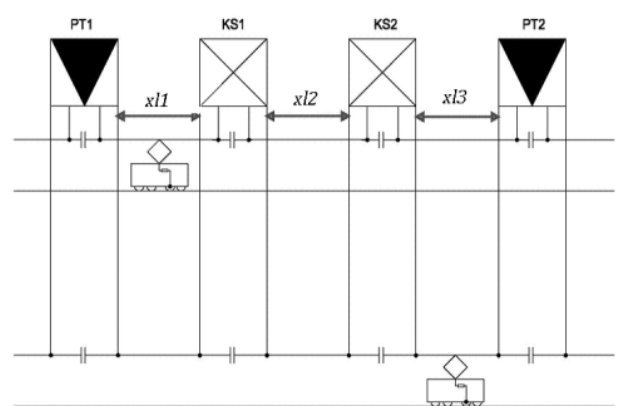

Rys. 1. Przykładowy odcinek zasilania $z$ dwoma kabinami sekcyjnymi. PT1 - podstacja trakcyjna 1 analizowanego odcinka zasilania, PT2 - podstacja trakcyjna 2 analizowanego odcinka zasilania, KSI - kabina sekcyjna 1 analizowane go odcinka zasilania, KS2 - kabina sekcyjna 2 analizowanego odcinka zasilania, xl1-odległość pomięzy PT1 a KS1, xl2 - odleglość pomiędzy kabinami sekcyjnymi, xl3 - odlegtość pomiędzy KS2 a PT1

Tematyka obliczeń parametrów obciążenia układów zasilania trakcji prądu stałego nie jest nowa i sięga początków trakcji elektrycznej. Przedstawiony na rysunku obwód elektryczny można rozwiązać analitycznie wykorzystując ogólnie znane prawa elektrotechniki. Metody obliczania układów zasilania trakcyjnego są dostępne w bogatej literaturze $n p . w[2,4]$. Istnieją również metody wykreślne, opisane np. w [2]. Rozwiązując obwód należy pamiętać że w każdym kroku obliczeń struktura przedstawionego obwodu się zmienia. Przyjmując wykonanie obliczeń dla pojazdu trakcyjnego zmieniającego swoje położenie co 10 metrów, dla odcinka zasilania np. $15 \mathrm{~km}$ otrzymamy 1500 obwodów elektrycznych. Biorąc pod uwagę ilość potrzebnych równań dla rozwiązania jednego obwodu, można przyjąć że zadanie staje się nie wykonalne bez wspomagania komputerowego. Oczywiście 
dostępne są zaawansowane specjalistyczne programy użytkowe które pozwalają na sprawdzenie w symulacji funkcjonowania układu zasilania dla zadanych warunków ruchowych. Tego typu programy umożliwiają jednak obliczanie i symulowanie tylko układów zasilania trakcyjnego, nie mają możliwości rozbudowy o nowe funkcje a ich cena jest bardzo wysoka.

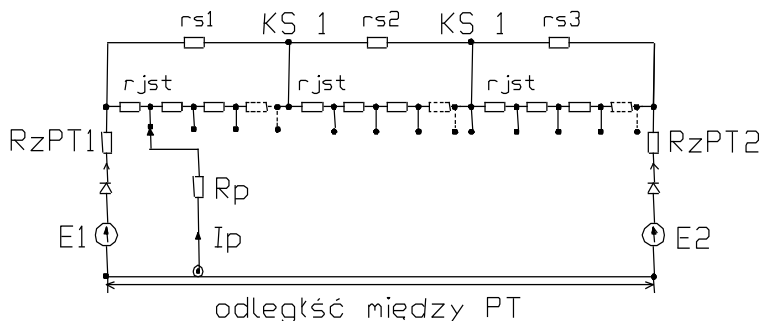

Rys. 2. Schemat zastępczy rozwiąywanego $w$ programie obwodu elektrycznego. RzPT1 - rezystancja zastepcza podstacji trakcyjnej PT1, RzPT2 - rezystancja zastępcza podstacji trakcyjnej PT2, Ip - prąd pobierany przez pociag $w$ danym położeniu na analizowanym odcinku, Rp - rezystancja zastępcza odzwierciedlająca rezystancję obwodu głównego pojazdu trakcyjnego, KSI - kabina sekcyjna l, KS2 - kabina sekcyjna 2, rjst - rezystancja jednostkowa sieci trakcyjnej wraz z siecia powrotna, rs1 - rezystancja zastepcza odcinka sieci trakcyjnej wraz z siecio powrotna na drugim torze pomiędzy PT1 i KS1, rs2 - rezystancja zastępcza odcinka sieci trakcyjnej wraz z siecia powrotna na drugim torze pomiędzy KS1 $i$ KS2, rs3 - rezystancja zastępcza odcinka sieci trakcyjnej wraz z siecia powrotna na drugim torze pomiędzy KS2 i PT2

Intencją autora jest opracowanie w pełni użytkowego programu obliczeniowo symulacyjnego, uruchamianego w ogólno dostępnym i tanim narzędziu inżynierskim jakim jest MATHCAD. Pierwszym blokiem tego programu jest blok obliczeniowy opisany w niniejszym artykule. Matematycznie prezentowany blok programu rozwiązuje przedstawiony obwód elektryczny metodą prądów oczkowych. Obliczenia są wykonywane w funkcji drogi pociągu, krok obliczeń może być ustawiany od $1 \mathrm{~m}$ do $1000 \mathrm{~m}$, ze względu na czas obliczeń domyślnie wynosi on $10 \mathrm{~m}$. Program umożliwia obliczenia dla jednorodnej rezystancji sieci trakcyjnej na całej długości oraz dla sieci trakcyjnej składającej się $\mathrm{z}$ odcinków rożnego typu a więc różnej rezystancji. Ta możliwość jest szczególnie przydatna $\mathrm{w}$ obliczeniach dla istniejących odcinków sieci trakcyjnej, gdzie sieć trakcyjna często składa się kilku lub nawet kilkunastu rodzajów o innej rezystancji każda. W programie możliwe są następujące warianty obliczeń:

1) Obliczenia dla stałego i zadanego prądu pociągu na całej trasie. Dla tego wariantu obliczeń program wyznacza napięcie na pantografie, prąd zasilacza podstacji trakcyjnej PT1 oraz prąd zasilacza podstacji trakcyjnej PT2.

2) Obliczenia dla prądu pociągu wynikającego ze stałej rezystancji Rp (rezystancji zastępczej odzwierciedlającej rezystancję obwodu głównego pojazdu trakcyjnego) na całej trasie. Dla tego wariantu obliczeń program wyznacza napięcie na pantografie, prąd zasilacza podstacji trakcyjnej PT1 oraz prąd zasilacza podstacji trakcyjnej PT2, oraz prąd pobierany przez pociąg.
3) Obliczenia dla prądu pociagu wynikającego z zadanej prędkości przejazdu, parametrów pociągu i parametrów trasy. Dla tego wariantu, program oblicza przejazd teoretyczny, wyznacza całkowite opory ruchu, sprawdza czy zadana prędkość dla danego pociągu i trasy jest możliwa do uzyskania. Po wyliczeniu program wyznacza napięcie na pantografie, prąd zasilacza podstacji trakcyjnej PT1, prąd zasilacza podstacji trakcyjnej PT2, oraz prąd pobierany przez pociąg. Oblicza czas przejazdu oraz ogólne zużycie energii elektrycznej. Przy obliczaniu napięcia na pantografie pojazdu trakcyjnego poruszającego się po torze 1 zastosowano założenie obciążenia skupionego na tym torze, natomiast na drugim torze obciążenia rozłożonego [2].

Ponadto program umożliwia wyliczenie prądu zwarcia występującego w dowolnym miejscu sieci trakcyjnej, w każdym $\mathrm{z}$ trzech wariantów, oraz inne parametry układu zasilania trakcyjnego $\mathrm{np}$. procentowego spadku napięcia zasilania AC podstacji trakcyjnych do którego wyliczenia konieczne jest podanie mocy zwarciowej podstacji trakcyjnych.

\section{Interfejs i dane konieczne do przeprowadzenia obliczeń}

Interfejs programu jest $\mathrm{w}$ ten sposób zaprojektowany, że obliczenia może wykonywać użytkownik nieznający zaawansowanych reguł obliczeń i programowania w MATHCADzie. Wszystkie konieczne dane wprowadza się w przygotowane tabele i okienka. Część obliczeniowa wykonywana jest $\mathrm{w}$ blokach ukrytych programu. Wyniki przedstawiane są po przewinięciu paska przewijania na koniec strony, mogą być też eksportowane do innych programów, na przykład arkusza kalkulacyjnego. Rysunek 3. przedstawia interfejs programu w części wprowadzania danych dotyczących sieci trakcyjnej i układu zasilania.

Program do przeprowadzenia obliczeń wymaga wprowadzenia danych zależnych od wybranego wariantu obliczeń. Dla każdego z trzech wariantów, konieczne jest podanie odległości między podstacjami trakcyjnymi i kabinami sekcyjnymi, rezystancji wewnętrznej podstacji trakcyjnych, wartości napięć nieobciążonych podstacji trakcyjnych, napięć zasilania podstacji trakcyjnych. Możliwe jest również podanie prądu dodatkowego wpływającego lub wypływającego $\mathrm{z}$ analizowanego odcinka. W wariancie pierwszym obliczeń program wymaga wprowadzenia prądu pociągu, który jest stały i pobierany przez pociąg na całej trasie, w wariancie drugim obliczeń należy podać rezystancję pociągu Rp (odzwierciedlającą rezystancje obwodu głównego pojazdu trakcyjnego), która jest stała na całej trasie. Do przeprowadzenia wariantu trzeciego, konieczna jest znajomość parametrów trasy tj. profilu poziomego i pionowego, znajomość charakterystyki trakcyjnej pojazdu trakcyjnego i odpowiadającej jej charakterystyki prądowej, konieczne są również dane pociągu tj. liczba i rodzaj wagonów, masa pociągu, masa lokomotywy.

Program do obliczania napięć i prądów w sieci trakcyjnej
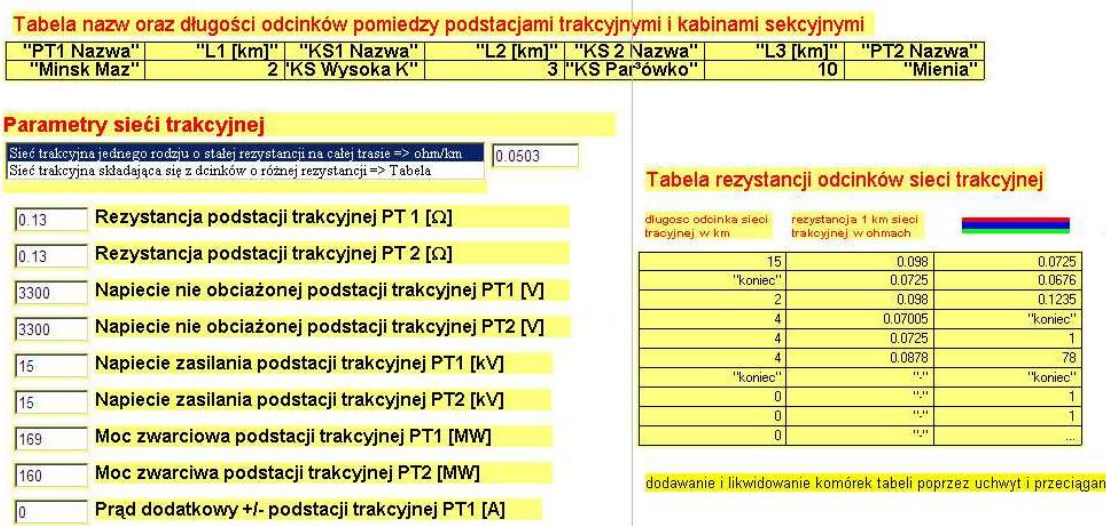


\section{Przykładowe wyniki obliczeń}

\subsection{Przykłady obliczeń dla jednostronnego układu} zasilania bez kabiny sekcyjnej

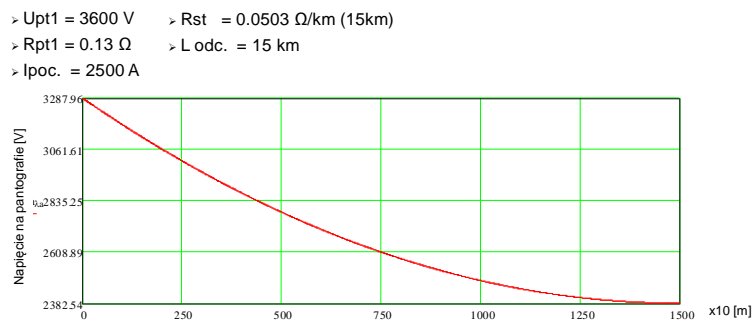

Uśr_uż $=2684 \quad \mathrm{~V} \quad$ mnapięcie średnie użyteczne napantografie $U \min =2382 \quad \mathrm{~V}$-napięcie minimalnena pantografie

Rys. 4. Napięcie na pantografie dla dwutorowego jednostronnego uktadu zasilania, dla sieci trakcyjnej jednego rodzaju
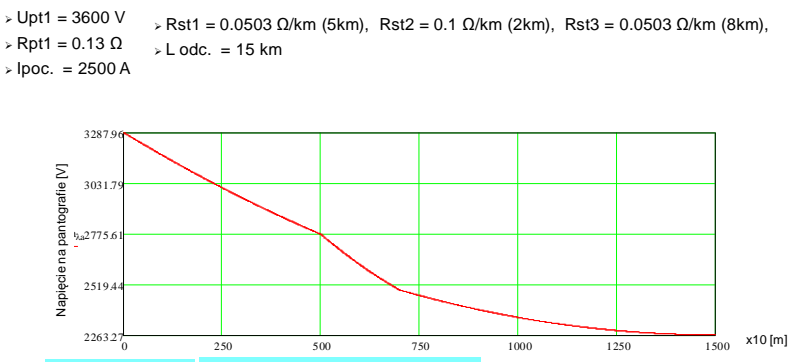

Uśr__uz $=26037 \mathrm{~V}$ napięcie średnie użyteczne na pantografie Umin $=2263 \mathrm{~V}$ napięcie minimalnena pantografie

Rys. 5. Napięcie na pantografie dla dwutorowego jednostronnego uktadu zasilania dla sieci trakcyjnej składającej się z odcinków różnego rodzaju

, Upt1 $=3600 \mathrm{~V}$, Rst $1=0.0503 \Omega / \mathrm{km}(15 \mathrm{~km})$

$\rightarrow$ Rpt $1=0.13 \Omega \quad$, Lodc. $=15 \mathrm{~km}$

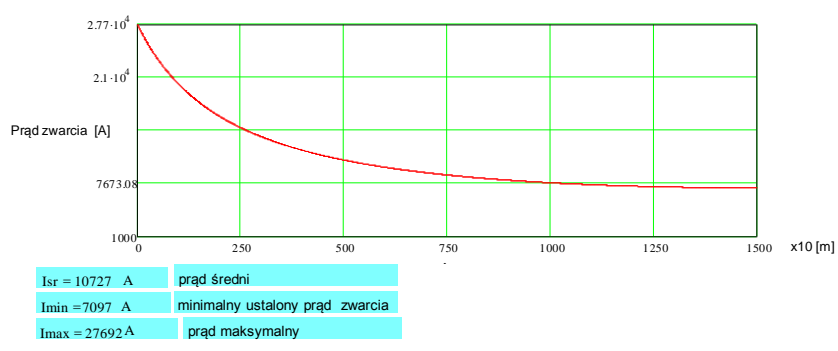

Rys. 6. Ustalony prądu zwarcia dla dwutorowego jednostronnego uktadu zasilania

\subsection{Przykłady obliczeń dla dwustronnego układu} zasilania bez kabiny sekcyjnej

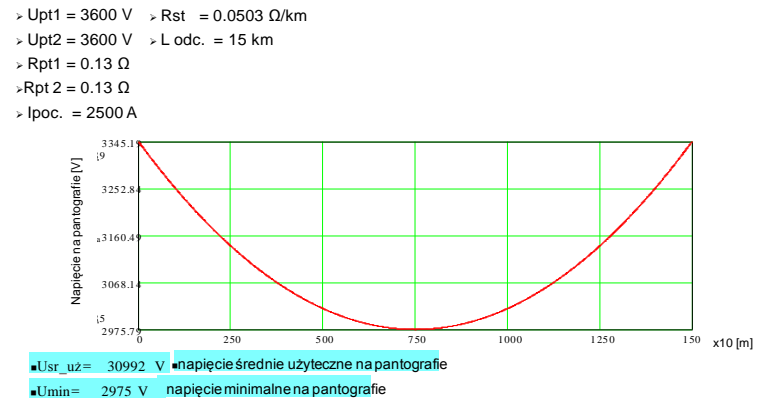

Rys. 7. Napięcie na pantografie dla dwutorowego dwustronnego uktadu zasilania bez kabiny sekcyjnej

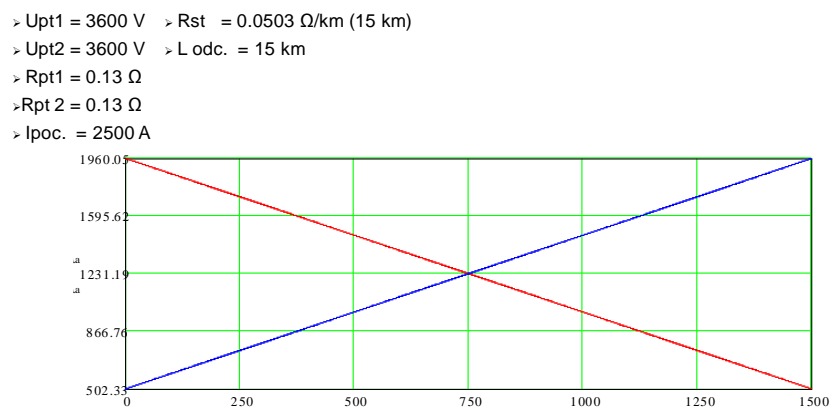

Rys. 8. Prad obciązenia zasilaczy PT dla dwutorowego dwustronnego uktadu zasilania, bez kabiny sekcyjnej

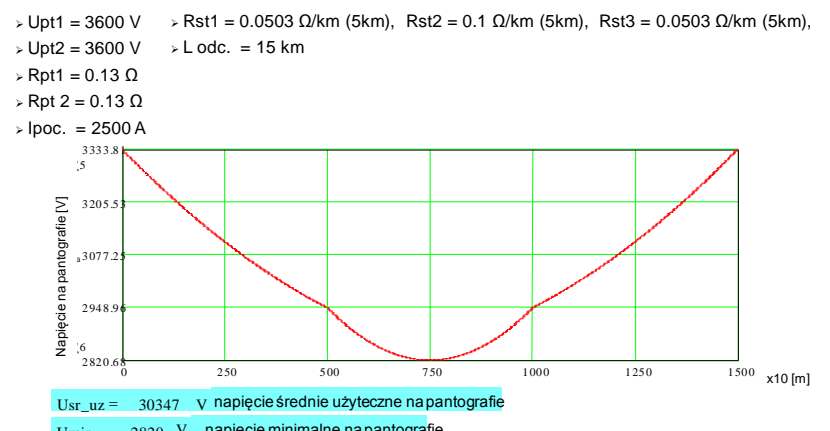

Rys. 9. Napięcie na pantografie dla dwutorowego dwustronnego uktadu zasilania, bez kabiny sekcyjnej, dla sieci trakcyjnej na odcinku $5 \mathrm{~km}$ o zwiększonej rezystancji

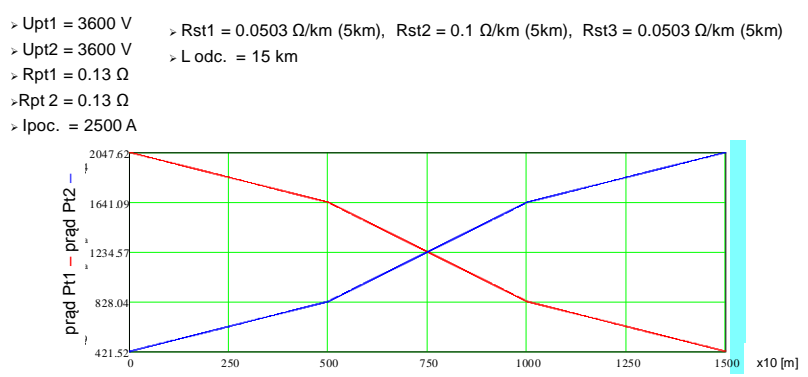

Rys. 10. Pradu obciażenia zasilaczy PT dla dwutorowego dwustronnego układu zasilania, bez kabiny sekcyjnej dla sieci trakcyjnej na odcinku $5 \mathrm{~km}$ o zwiększonej rezystancji

\subsection{Przykłady obliczeń dla dwustronnego układu zasilania z dwoma kabinami sekcyjnymi}

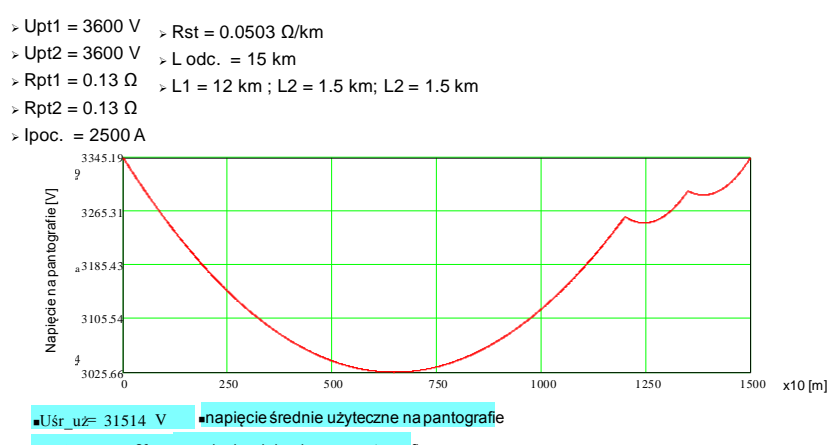

.Umin $=3025 \mathrm{~V}$ napięcieminimalnena pantografie

Rys. 11. Napięcie na pantografie dla dwutorowego dwustronnego uktadu zasilania, z dwiema kabinami sekcyjnymi $12 \mathrm{~km}$ i $13,5 \mathrm{~km}$ od PT1 

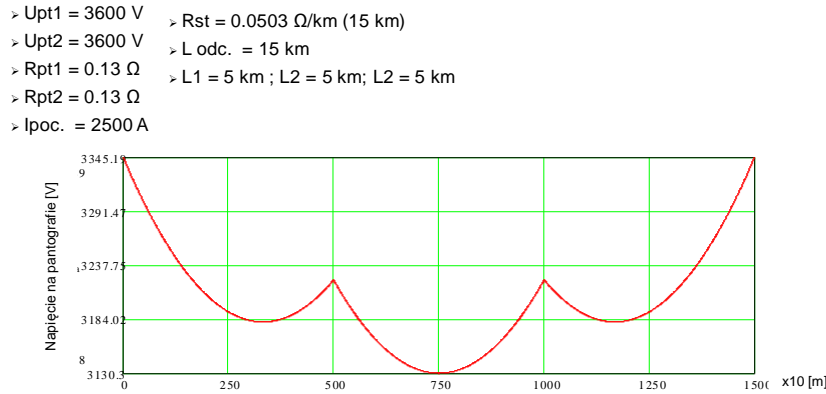

Uśr_už $=3202 \mathrm{~V} \quad$ napięcie średnie użyteczne na pantografie Umin $=3130 \mathrm{~V}$ napięcie minimalne na pantografie

Rys. 12. Napięcie na pantografie dla dwutorowego dwustronnego uktadu zasilania, z dwiema kabinami sekcyjnymi oddalonymi $5 \mathrm{~km}$ i $10 \mathrm{~km}$ od PTI

\section{- Upt $1=3600 \mathrm{~V}$}

Upt2 $=3600 \mathrm{~V}>$ Rst $=0.0503 \Omega / \mathrm{km}(15 \mathrm{~km})$

Rpt1 $=0.13 \Omega>$ Lodc. $=15 \mathrm{~km}$

$>$ Rpt2 $=0.13 \Omega \quad>\mathrm{L} 1=12 \mathrm{~km} ; \mathrm{L} 2=1.5 \mathrm{~km} ; \mathrm{L} 2=1.5 \mathrm{~km}$

, Ipoc. $=2500 \mathrm{~A}$

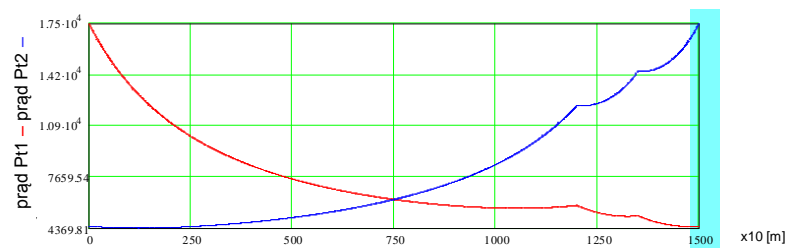

Rys. 13. Prad zwarcia zasilaczy PT dla dwutorowego dwustronnego uktadu zasilania, $z$ dwiema kabinami sekcyjnymi oddalonymi $12 \mathrm{~km}$ i $13,5 \mathrm{~km}$ od PTI

\subsection{Przykładowe wyniki symulacji dla wariantu trzeciego obliczeń}
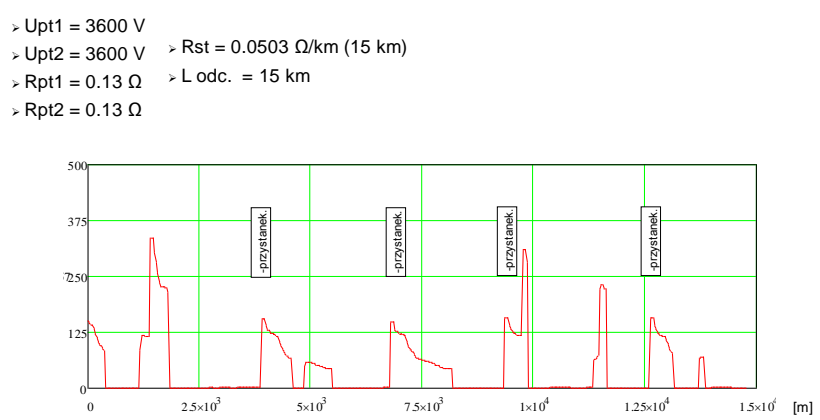

Rys. 14. Symulacja pradu pobieranego przez EZT EN 57 dla dwutorowego dwustronnego uktadu zasilania

, Upt1 $=3600 \mathrm{~V}$

$\rightarrow$ Upt2 $=3600 \mathrm{~V}>\mathrm{Rst}=0.0503 \Omega / \mathrm{km}(15 \mathrm{~km})$

Rpt1 $=0.13 \Omega \rightarrow L$ odc $=15 \mathrm{~km}$

$>$ Rpt2 $=0.13 \Omega$

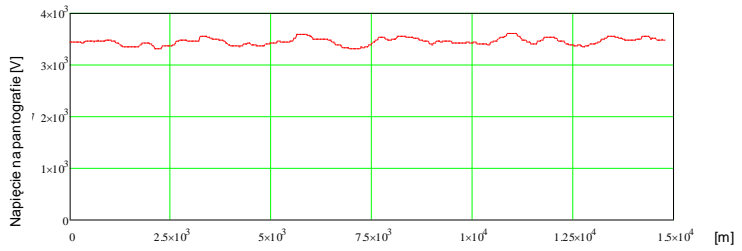

Rys. 15. Symulacja napięcia na pantografie dla EZT EN 57 dla dwutorowego dwustronnego układu zasilania

\section{Podsumowanie}

Wydawać by się mogło że przedstawione obliczenia są trywialne do wykonania. Autor uważa jednak że możliwość przeprowadzenia takich obliczeń w kilka sekund, dla każdych dowolnie zadanych parametrów układu zasilania trakcyjnego, dla dowolnie długiego odcinka i dowolnie rozstawionych kabin sekcyjnych, oraz dla różnej jednostkowej rezystancji sieci trakcyjnej, w ogólnie dostępnym i tanim uniwersalnym narzędziu inżynierskim jest zaletą takiego podejścia do problemu obliczeń trakcyjnych. Zaletą oprogramowania uniwersalnego inżynierskiego jakim jest MATHCAD jest również możliwość łatwej rozbudowy o kolejne bloki obliczeniowe w zależności od potrzeb użytkownika.

Oprogramowanie MATHCAD może być szeroko wykorzystywane w obliczeniach i symulacji parametrów układów zasilania sieci trakcyjnej. Przedstawiony blok programu obliczeniowego jest częścią składową większego opracowywanego pakietu obliczeniowo symulacyjnego, który umożliwi sprawdzenie parametrów układu zasilania, decydujących o interoperacyjności. Kolejne bloki obliczeniowo symulacyjne umożliwią obliczenia dla wielu pociągów na odcinku zasilania poruszających się według zadanego rozkładu jazdy, pozwolą na wyznaczenie dopuszczalnego maksymalnego następstwa pociągów. Według autora pakiet ten będzie mógł być wykorzystywany również na etapie projektowania oraz weryfikacji projektu. Łatwy interfejs umożliwia użytkowanie użytkownikom bez znajomości zaawansowanych reguł obsługi MATHCADa. Przedstawione w referacie wyniki obliczeń zweryfikowano $\mathrm{z}$ obliczonymi innymi metodami bardziej pracochłonnymi z wynikiem pozytywnym.

\section{Literatura}

[1] Decyzja Komisji 2011/274/UE z dnia 26 kwietnia 2011 r. dotycząca technicznej specyfikacji interoperacyjności podsystemu „Energia” transeuropejskiego systemu kolei konwencjonalnych.

[2] Mierzejewski L, Szeląg A, Gałuszewski M.: System zasilania trakcji elektrycznej prądu stałego. Wydawnictwa Politechniki Warszawskiej, Warszawa 1989.

[3] PN-EN 50388 Zastosowania kolejowe - System zasilania i tabor - Warunki techniczne koordynacji pomiędzy systemem zasilania (podstacja) i taborem w celu osiągnięcia interoperacyjności.

[4] Szeląg A.: Wpływ napięcia w sieci trakcyjnej $3 \mathrm{kV}$ DC na parametry energetyczno-trakcyjne zasilanych pojazdów.

\section{Mgr inż. Wlodzimierz Kruczek}

e-mail:wkruczek@ikolej.p

Od 2007r. pracownik Zakładu Elektroenergetyki Instytutu Kolejnictwa. Specjalista w zakresie miernictwa elektrycznego, pomiarów termowizyjnych, ochrony przeciwporażeniowej w systemach trakcyjnych, pojazdach trakcyjnych i wagonach osobowych. Od 2010 r. kierownik sekcji laboratoryjno pomiarowej w Zakładzie Elektroenergetyki. Zajmuje się również badaniami wyłączników szybkich, przetwornic statycznych, sieci trakcyjnej i odbieraków prądu pojazdów szynowych i ich współpracy z siecią trakcyjną. Autor i współautor ok. 15 prac badawczotechnicznych. Członek Komitetu Technicznego nr 73

PKN ds. Projektowania i Eksploatacji Urządzeń Elektroenergetycznych o Napięciu Powyżej $1 \mathrm{kV}$ Prądu Przemiennego (1,5 kV Prądu Stałego) oraz Ograniczników Przepięć. Doktorant w Instytucie Elektrotechniki.

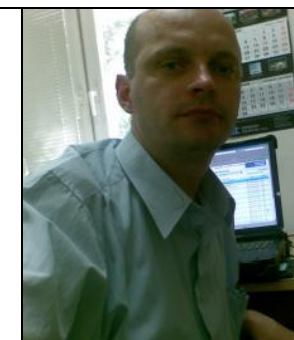

przyjęto do drukulaccepted: 14.10.2013 